\title{
A prospective study investigating gross motor function of children with cerebral palsy and GMFCS level II after long-term Botulinum toxin type A use
}

\author{
Jane Valentine ${ }^{1,2^{*}}$ (D), Sue-Anne Davidson ${ }^{2}$, Natasha Bear ${ }^{3}$, Eve Blair ${ }^{4}$, Lisa Paterson ${ }^{2}$, Roslyn Ward ${ }^{5}$,
}

David Forbes ${ }^{1}$ and Catherine Elliott ${ }^{5}$

\begin{abstract}
Background: The aim of this study is to contribute to the knowledge base on the long-term outcomes of evidence-based medical interventions used to improve gross motor function in children and adolescents with Cerebral Palsy.

Method: Prospective cohort study of children with Cerebral Palsy in the birth years 2000-2009 attending a tertiary level service for children with Cerebral Palsy who's first recorded Gross Motor Function Classification System level was II.

Results: A total of 40 children were eligible for the study, of whom 28 (72.7\%) enrolled. The Botulinum toxin A treatment for this cohort, (median and interquartile ranges) were: total number of lower limb Botulinum toxin A injections $11(6.7,5.5)$; total dose of Botulinum Toxin A per lower limb treatment $6.95 \mathrm{u} / \mathrm{kg}(4.5,11)$; and dose of Botulinum Toxin u/kg/muscle $2.95(2.2,4)$. For all 28 subjects there was a median of 15 (8.5 to 22) Gross Motor Function Classification System level recordings: six of the 28 children (21.4\%) improved from level II to level I, the remaining 22 children remained stable at level II (78.6\%). In this highly treated population, the average 66 item Gross Motor Function Measure score for the 22 children in level II was 72.55, which is consistent with the mean of 68.5 reported in the original Ontario cohort.
\end{abstract}

Conclusion: This cohort study has confirmed that children with Cerebral Palsy, Gross Motor Function level II treated at a young age with repeated doses of Botulinum Toxin A within an integrated comprehensive service, maintain or improve their functional motor level at a later age.

\section{Background}

Cerebral Palsy (CP), the most common motor disorder of childhood, was described by Rosenbaum et al. in 2007 as a 'group of permanent disorders of the development of movement and posture that are attributed to nonprogressive disturbances that occurred in the developing fetal or infant brain' $[1,2]$. The Australian Cerebral Palsy Register has recorded the prevalence of $\mathrm{CP}$ as 2.1 per

\footnotetext{
* Correspondence: jane.valentine@health.wa.gov.au

'School of Medicine, University of Western Australia, 35 Stirling Highway, Crawley, Western Australia 6009, Australia

2Department of Paediatric Rehabilitation, Perth Children's Hospital, Nedlands, Western Australia, Australia

Full list of author information is available at the end of the article
}

1000 live births [3]. Perth Children's Hospital (PCH), Western Australia (WA) (population 2.4 million) is the state centre for the management of motor disorders in children and adolescents with CP. In 2003 following new funding from the West Australian government an evidence-based clinical program for children with $\mathrm{CP}$ in WA was established and is known as the Cerebral Palsy Mobility Service (CPMS). As part of the funding a database, the Paediatric Rehabilitation Information System (PRIS), was established, with retrospective data entry for children with CP to 1995 [4]. In a recent retrospective audit, we confirmed that the CPMS manages the state-

(c) The Author(s). 2020 Open Access This article is distributed under the terms of the Creative Commons Attribution 4.0 International License (http://creativecommons.org/licenses/by/4.0/), which permits unrestricted use, distribution, and reproduction in any medium, provided you give appropriate credit to the original author(s) and the source, provide a link to the Creative Commons license, and indicate if changes were made. The Creative Commons Public Domain Dedication waiver (http://creativecommons.org/publicdomain/zero/1.0/) applies to the data made available in this article, unless otherwise stated. 
wide population of children and adolescents with $\mathrm{CP}$ in WA and provides accurate tracking of interventions [4].

Motor development, pain and integration into community life are primary concerns of parents of children with $\mathrm{CP}$ [5] and interventions including Botulinum toxin type A (BoNTA) and orthopaedic surgery are designed to improve motor function to allow participation, treat pain and prevent secondary impairments. BoNTA is an evidence based management for hypertonia in children with CP $[2,6,7]$. BoNTA has been used to manage hypertonia in children with CP since 1993 [8]. BoNTA has a high safety profile [9-11] and the short-term outcomes of BoNTA are well documented [12-20]. Molenaers et al., concluded that when injected according to an integrated approach and started at a young age, BoNTA has the potential to improve overall function of children with CP [21]. However as documented by Kahraman in their systematic review and others there is little evidence on the outcome of repeated BoNTA injections over time [22-24] and the long-term effect of BoNTA on muscle size and morphology in children with CP remains under investigation $[25,26]$.

The evidence base for interventions that are proven effective in children with $\mathrm{CP}$ is limited with the majority of interventions only having evidence for short-term gains [7]. Two recent Delphi surveys of consumers, researchers and clinicians have identified the need to provide evidence of longer-term outcomes of interventions for children with CP $[27,28]$.

\section{Methods}

The aim of this study is to contribute to the knowledge base on the long-term outcomes of evidence-based medical interventions used to improve motor function in children and adolescents with CP. In this cohort study we will compare the observed gross motor function profiles of children with $\mathrm{CP}$ whose first recorded Gross Motor Function Classification System (GMFCS) level was level II and who are currently aged between 8 and 16 years and enrolled in the CPMS, with their predicted average 66 item Gross Motor Function Measure (GMFM-66) score on the Ontario Motor Growth Curves [29] for their current GMFCS level. We will also measure the pain and participation levels of these children. The primary question is: 'Do children treated at a young age with repeated doses of BoNTA within an integrated comprehensive service, maintain their functional motor gains at a later age?' The secondary question is: 'What are the comorbidities, pain and participation profiles of these children?'

This prospective cohort study includes children with CP whose first recorded GMFCS level was level II, who are in the birth cohort 2000-2009 inclusive (aged 8-16 years at time of assessment) and currently enrolled in the CPMS. Exclusion criteria included a lack of GMFCS level recorded at time point 1 , BoNTA treatment external to our CPMS service, history of selective dorsal root rhizotomy, declining to participate or inability to comply with assessments. Data concerning enrolled children was obtained at two time points: time point 1, the time of entry of the child into the CPMS for treatment; and time point 2, is at the date of motor assessments and questionnaires.

Data for time point 1 is data taken from the CPMS database records and includes topographical classification (hemiplegia, diplegia etc.), comorbidities and GMFCS level. Data for time point 2 includes the functional motor assessments GMFCS and GMFM-66. The GMFM-66 is a valid and reliable measure [30], we used the Gross Motor Ability Estimator (GMAE-2) computer program to estimate a total GMFM-66 score [30]. To interpret the GMFM-66 scores, we compared the score to the predicted GMFM-66 score for the GMFCS level on the 'Percentiles by Age', Ontario Motor Growth Curves [31].

The Brief Pain Inventory - Short Form [32] was used to record pain history. This questionnaire comprises two parts: the first part contains eight items regarding pain location, pain severity, analgesics used and pain relief; the second part asks the individual about pain interference with activities in daily life. The Participation and Environment Measure for Children and Youth (PEM$\mathrm{CY})$ short form was used to measure activity and participation [33]; this is a parent-report instrument that examines participation and environment factors that affect the participation of children across three settings: home, school and community. Parents are asked to rate their child's involvement in 25 activities across the three settings. A questionnaire concerning medication use was completed and anthropometric measures to calculate body mass index (BMI) $\mathrm{z}$ scores were also taken. All assessments were done by a qualified physiotherapist (author LP) while the patient was attending an outpatient clinic.

At time point 2, data was also extracted from PRIS concerning the date of birth of the child and the date, type and GMFCS level for each intervention. In view of our focus on GMFCS in this report, the details for BoNTA intervention data was limited to the lower limb use. BoNTA data extracted included muscle treatment site(s), total lower limb dose of BoNTA $(\mathrm{u} / \mathrm{kg})$, BoNTA dose per muscle $(\mathrm{u} / \mathrm{kg} /$ muscle), and indications for use of BoNTA. Our service has only ever used Onabotulinum toxin (Allergan) as our BoNTA treatment. Treatment sites are recorded as distal if involving muscles that insert below the knee joint, proximal if muscles insert above the knee (including psoas) and multilevel if both distal and proximal muscles were treated. Indications for use of BoNTA were recorded as improve 
function', 'manage symptoms' (including pain and splint tolerance) and 'care and comfort'. It is possible to have multiple indications for each treatment. The data fields concerning indications for use were only introduced into the database in 2013 so data for this field is incomplete. In view of our focus on GMFCS, in this report only the details for lower limb orthopaedic surgery are provided and indications for surgery are coded as hip only, gait only, function only or a combination of these.

\section{Data analysis}

Age was calculated in months and then converted to years from the date of birth. The GMFCS level was classified initially according to Palisano (1997) and from 2007 onwards according to the GMFCS Extended and Revised version [29, 34]. Although the GMFCS level was assessed at each clinic visit, it is updated on PRIS only if the GMFCS level changes. To assess GMFCS level stability, the first and last GMFCS level recorded were compared. Children and adolescents who no longer need treatment by the CPMS are discharged from the service but are eligible for re-referral from the community if required. The reasons for discharge include stable function with no further treatment considered likely to be needed, patient deceased or, for a very small number, relocation of the family.

Continuous variables are reported as means and standard deviations or medians and interquartile ranges (when distributions were skewed). Categorical variables are reported as frequencies and percentages. Relationships between categorical variables (BoNTA use in multilevel muscles vs topography, pain and BMI) were compared using chi square test. PEMCY and topography, GMFCS, pain and BMI (categories) was compared using the Mann Whitney U test. PEMCY and GMFM was analysed using linear regression and Pearsons correlation coefficients. All data was analysed using Stata 14.1 (StataCorp, College Station, TX). Statistical significance was considered $p<0.05$.

\section{Results}

There were 766 children aged between 8 and 16 years at the time of assessment. At time point 1, 163 of these children (21.3\%) were recorded at GFMCS level II. Figure 1 outlines the patient flow through the clinical service. There were 55 individuals potentially eligible for enrolment in the study; of these, 15 (27.3\%) were excluded as they either declined $(n=8)$ or they were unable to comply $(n=7)$ due to comorbidities, including autism and intellectual disability. A total of 40 children were eligible, of whom 28 (72.7\%) were enrolled and assessed. These 28 children represent a sample of convenience of the total 40 children who could be assessed as the study was conducted over a limited time period in a busy clinical service.

Of the 108 children no longer in the service, the majority (96 children) were discharged as their motor function was stable and it was considered they were unlikely to require future BoNTA treatment. Of these 108 children, only $65(60 \%)$ had ever received BoNTA. Of these 65 children, the median (IQR [interquartile range]) age at last dose of BoNTA was $9(6,11)$ years with a median (IQR) of $5(2,12)$ lower limb BoNTA treatments. For these 108 children, 24 (22\%) had improved to become GMFCS level I, 72 (67\%) were stable at GMFCS level II, and $12(11 \%)$ deteriorated - 10 to GMFCS level III and two to GMFCS level IV.

The median (IQR) age of the 108 excluded children was $13.3(11.7,15.6)$ years compared with $11.5(10,12.7)$ years of the 55 potentially eligible children. 54 of the 55 (98\%) of the eligible children received BoNTA. Table 1 compares $\mathrm{CP}$ topography, comorbidity rates and BoNTA use between the 55 enrolled and non-enrolled potentially eligible children. These two groups were similar in topography, age and comorbidities rate but the median number of BoNTA treatments was lower in the nonenrolled group.

Table 2 details $\mathrm{CP}$ topography predominate motor type, comorbidities, functional levels, BoNTA dosing, muscle injection level distribution and GMFM scores for the 28 enrolled children. Their median (IQR) age was $10.9(10,11.8)$ years. Diplegia topography was observed in 15 (53.6\%) children and hemiplegic in $13(46.4 \%)$ children. Comorbidity rates were high with 15 (54\%) of the group reported to have comorbidities that included intellectual disability, epilepsy and autism. The mean BMI z score was 0.3 (SD 1.1) with 21 (75\%) of the children a normal weight for their age, $5(17.9 \%)$ overweight and 2 (7.9\%) obese.

Of the 28 children in this cohort, 27 received treatment with BoNTA, the median (IQR) total dose of BoNTA to lower limbs per treatment was $6.95 \mathrm{u} / \mathrm{kg}(4.5$, 11) and the median (IQR) dose of BoNTA $\mathrm{u} / \mathrm{kg} /$ muscle was $2.95(2.2,4)$. The distribution of the BoNTA in the lower limb muscles by age and topography is documented in Fig. 2. There was a higher use of BoNTA in multilevel muscles in children with diplegia compared to those with hemiplegia $(p<0.001)$. None of the 28 children were on any additional medication to modulate tone or movement disorders. For children with hemiplegia the average time between injections was 8.5 months (SD 2.4 months) and for children with diplegia the average time between injections was 7.2 months (SD 3.6 months).

For all 28 subjects there was a median (IQR) of 15 $(8.5,22)$ GMFCS recordings done. Of these 28 children, six (21.4\%) improved to GMFCS level I. The average 


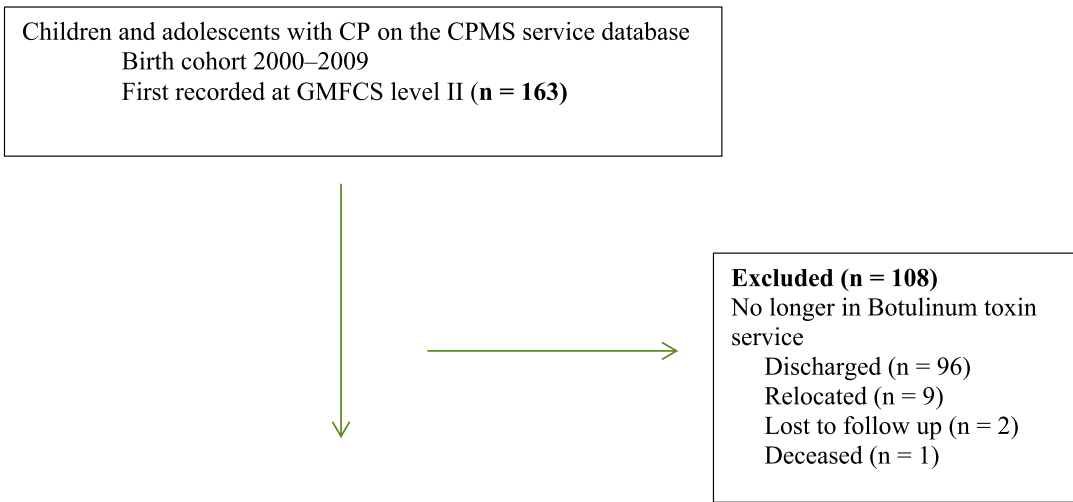

Currently attending Botulinum toxin clinical service Invited to enrol $(\mathbf{n}=\mathbf{5 5})$

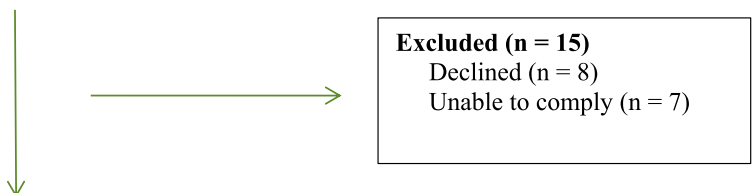

Eligible to enrol $(n=\mathbf{4 0})$

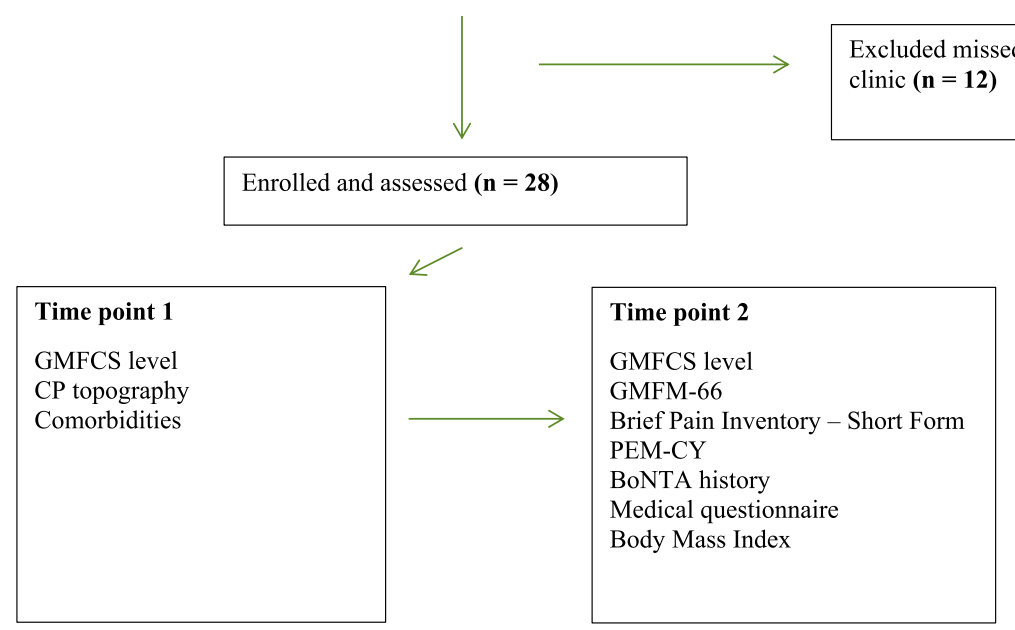

Fig. 1 Flow diagram of enrolment

GMFM-66 centile score for age and GMFCS level for these six children was 46, with a mean GMFM-66 score of 86.9. The age when BoNTA treatments were received, the recorded GMFCS and GMFM level, and the comorbidities of these six children are documented in Fig. 3. Notably, five of these six individuals had a hemiplegic distribution and only two of the six had comorbidities.

Of the 22 children who remained GMFCS level II at time point 2, the average GMFM-66 centile for GMFCS level II was 56.7, with a mean GMFM-66 score of 72.55 and average age of 11.2 years. Only eight of the 22 children received the same GMFCS rating at all assessments, with a median (IQR) of $16(7,19)$ GMFCS recordings.
No child increased their final GMFCS level recording, that is, deteriorated in gross motor function.

The Brief Pain Inventory - Short Form was completed by 26 of the 28 enrolled children. Pain, other than everyday kinds of pain such as toothache or minor headache, was present in 10 of the 28 children (38.5\%), and the average pain rating was 3 out of 10 (SD 2.4). Of those 10 children with pain, $5(50 \%)$ felt the pain interfered with their general activity and rated the average amount of interference as median (IQR) of $1(0,7)$. Of the 10 children with pain, 5 (50\%) had comorbidities; and of the 18 children with no pain, 10 (56\%) had comorbidities, a similar ratio. There was no association with pain being 


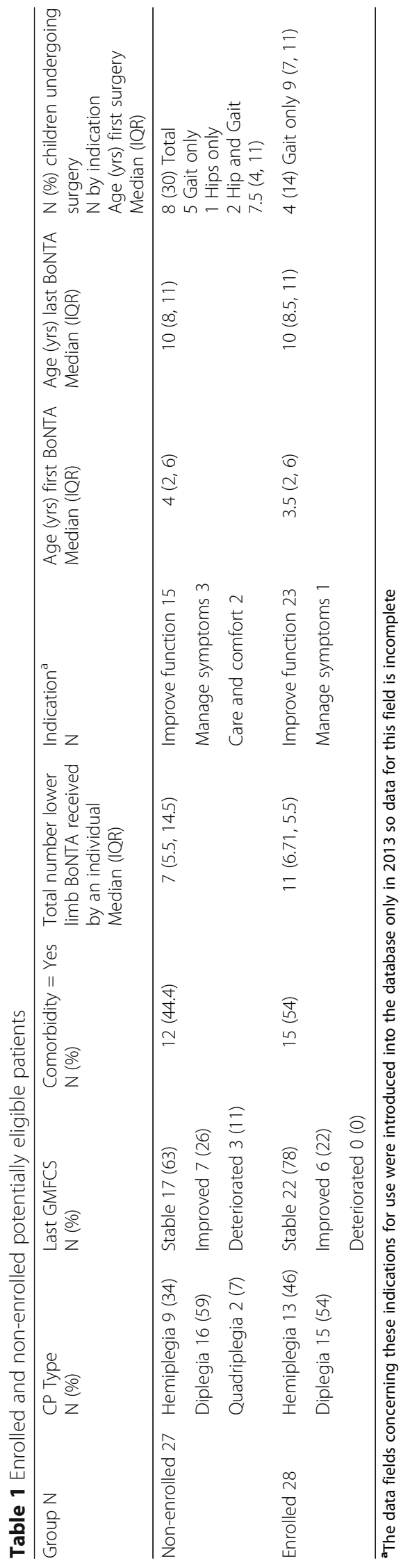




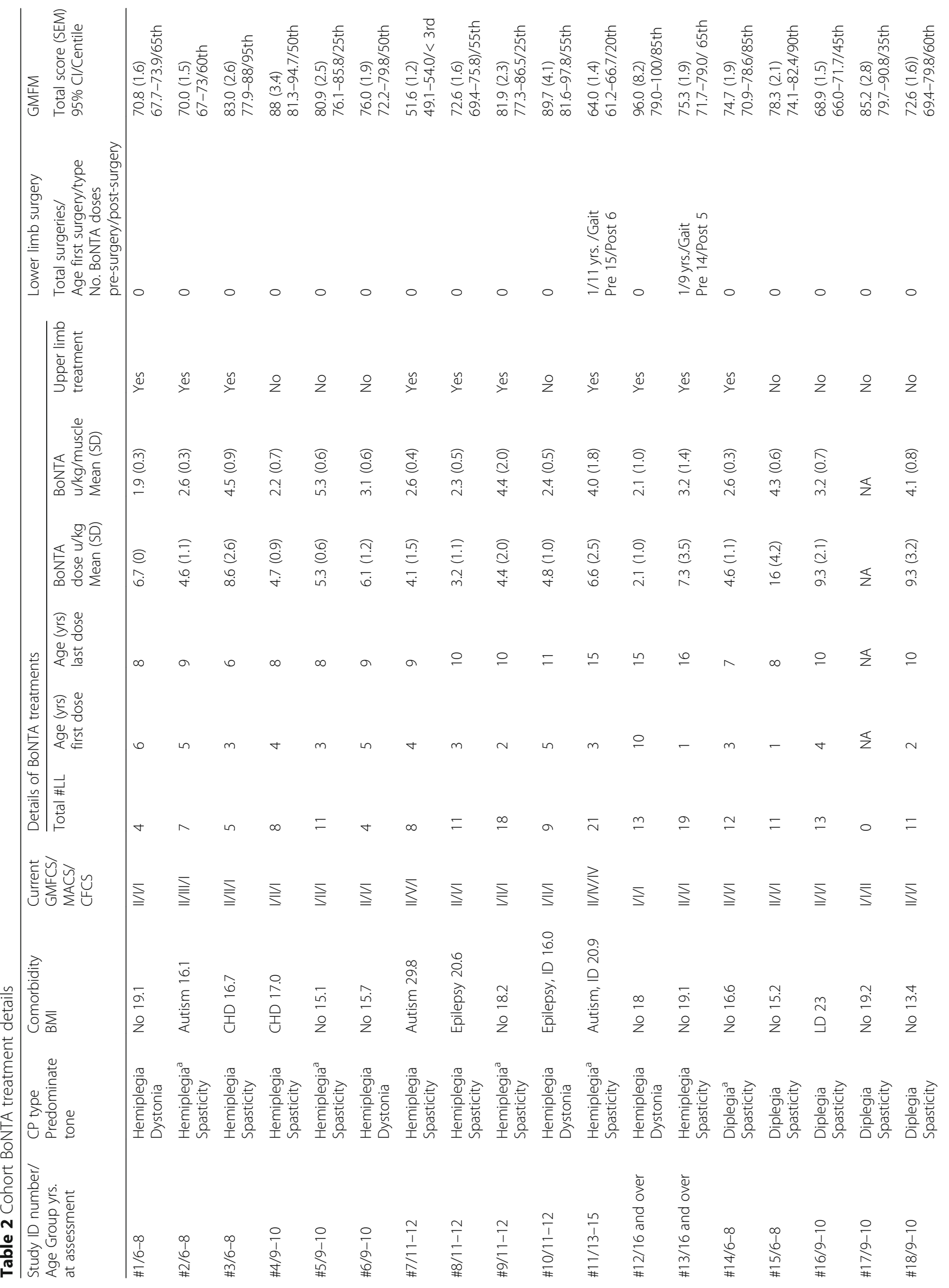




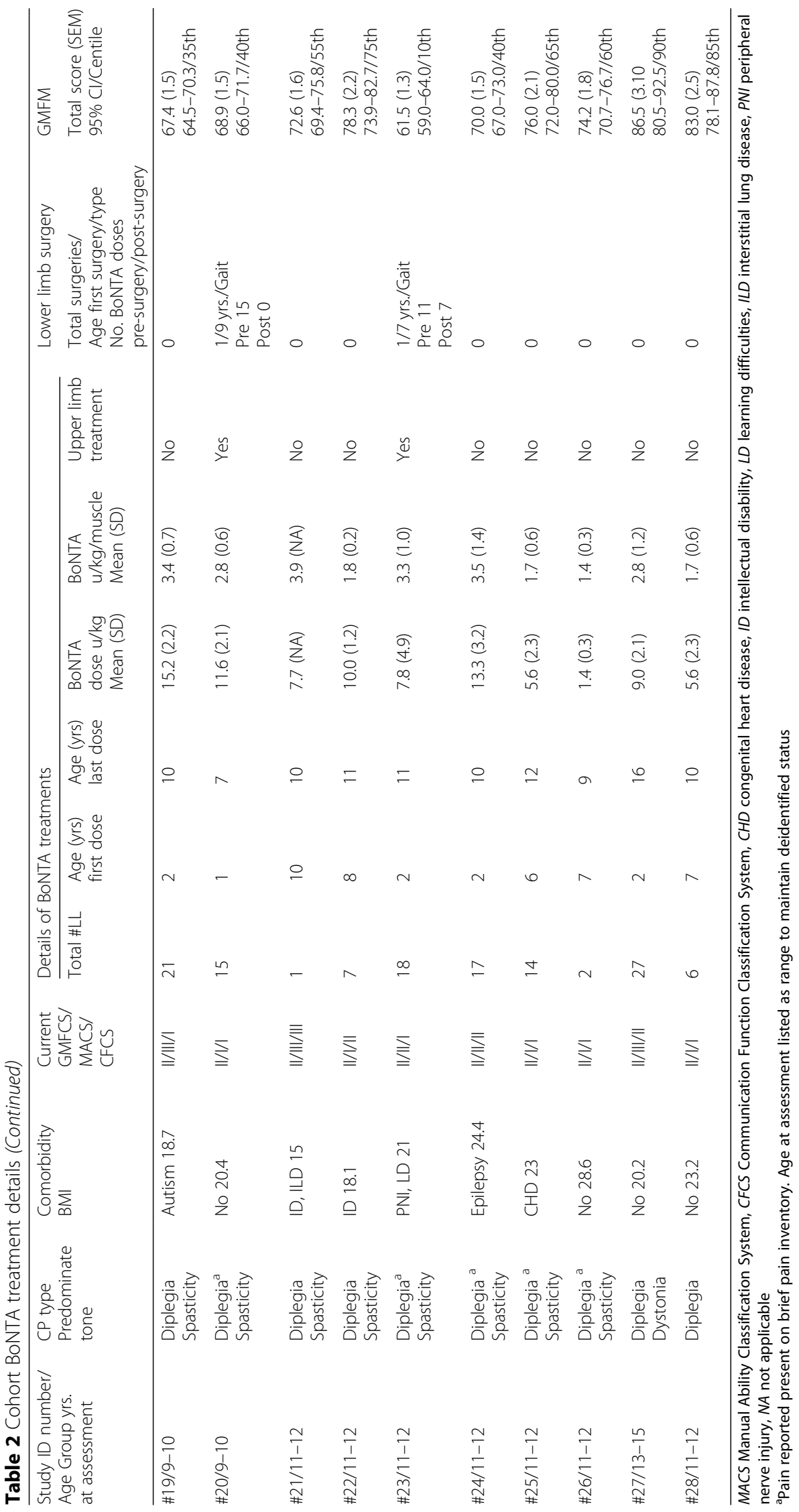




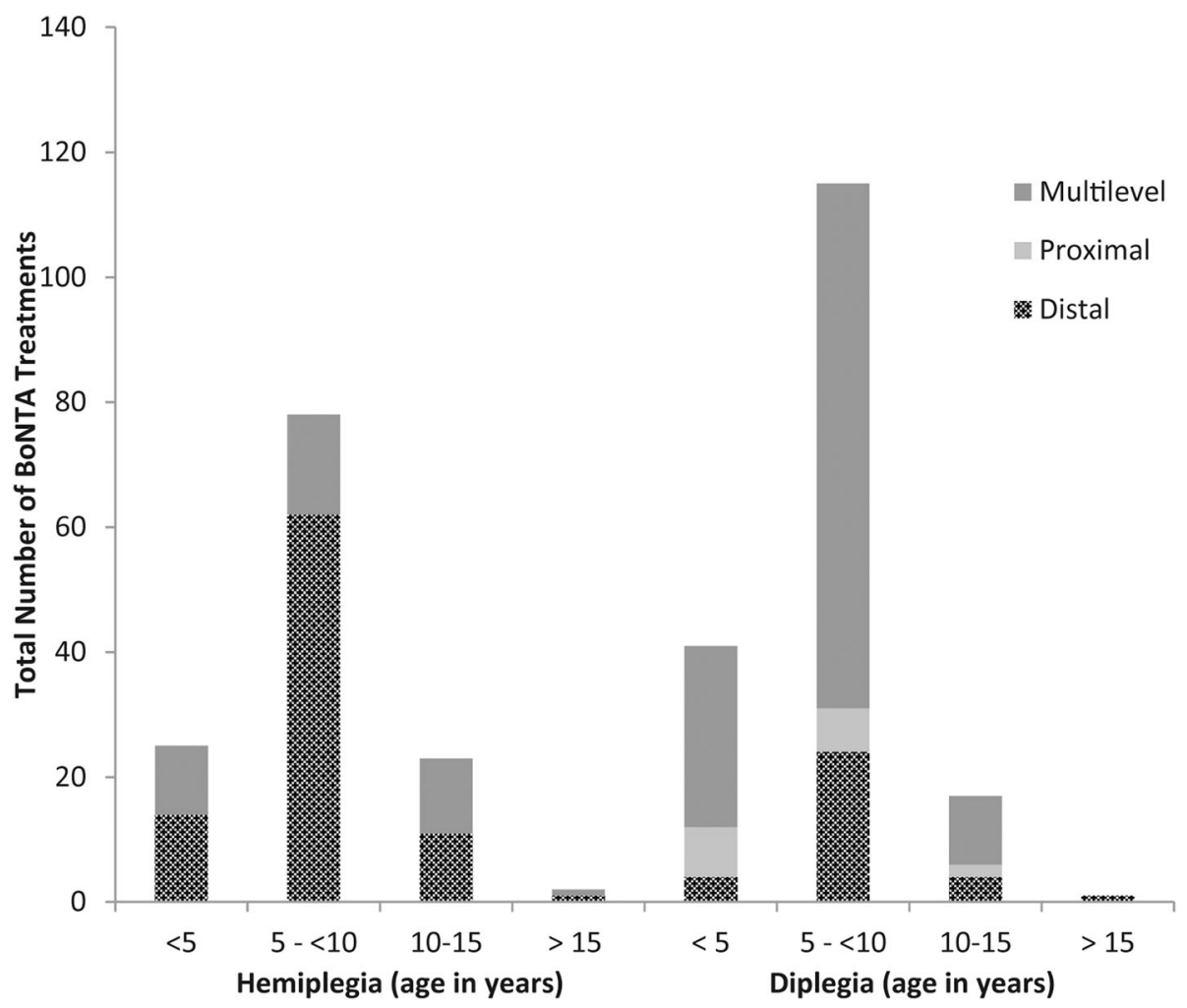

Fig. 2 Total number of BoNTA treatment by CP topography and age

present and a BMI in the obese or overweight range $(p=0.157)$.

The median (IQR) PEM-CY scores for all of the cohort participation in the three domains were: home 6.1 (5.4, 6.5), school $3.6(3,4,4.6)$ and community $2.2(1.6,3.0)$. There was no statistically significant relationship between the PEM-CY score and topography, final GMFCS level or pain scores, see Table 3. Correlation and linear regression of PEM-CY and GMFM is shown in Table 4, with no significant association between these two measures in either home or community. Interestingly there was a statistically significant negative association between school participation and GMFM centile with a correlation coefficient of $-0.5(p=0.010)$.

\section{Discussion}

Our study confirms that the majority of ambulant children treated at a young age with repeated doses of BoNTA within an integrated comprehensive service, maintain their functional motor levels over time, as documented by the GMFCS level. The rates of pain and participation in our cohort are similar to that documented in other populations [35-39]. Our rates of GMFCS stability in this treated population are also similar to those recently documented in large cohort studies [40, 41]. As the GMFCS is a classification system rather than an outcome measure, we used the GMFM - 66 [30] to look at our population's motor function in more detail. As documented by Hanna et al. for children in GMFCS levels I and II, the average age at which children achieve $90 \%$ of their expected limit in GMFM-66 motor ability is 5 years 2 months for GMFCS I and 4 years 11 months for GMFCS II, they found no evidence of functional decline, on average, for children in GMFCS levels I and II [42]. The median age of our cohort at the time of GMFM-66 assessment was 11.5 years, so it can be presumed that at the age at which we assessed GMFM-66 our patients have achieved motor stability. Importantly we have shown that in this highly treated population, the average GMFM-66 limit of our children in GMFCS level II is 72.55, which is consistent with the mean of 68.5 reported by Hanna [42]. For our children who became GMFCS level I, the average GMFM-66 limit was 86.9 , again consistent with the average of 89.5 reported by Hanna et al. [42] Figure 3 provided detailed information on the small case series of patients who improved GMFCS level following treatment in our comprehensive service. For patients 12 and 4, both of whom have received multiple series of BoNTA treatments, we propose that these patients have permanently changed GMFCS level as they had their first recordings of GMFCS level II made after the age of 4 years, which is when the GMFCS 


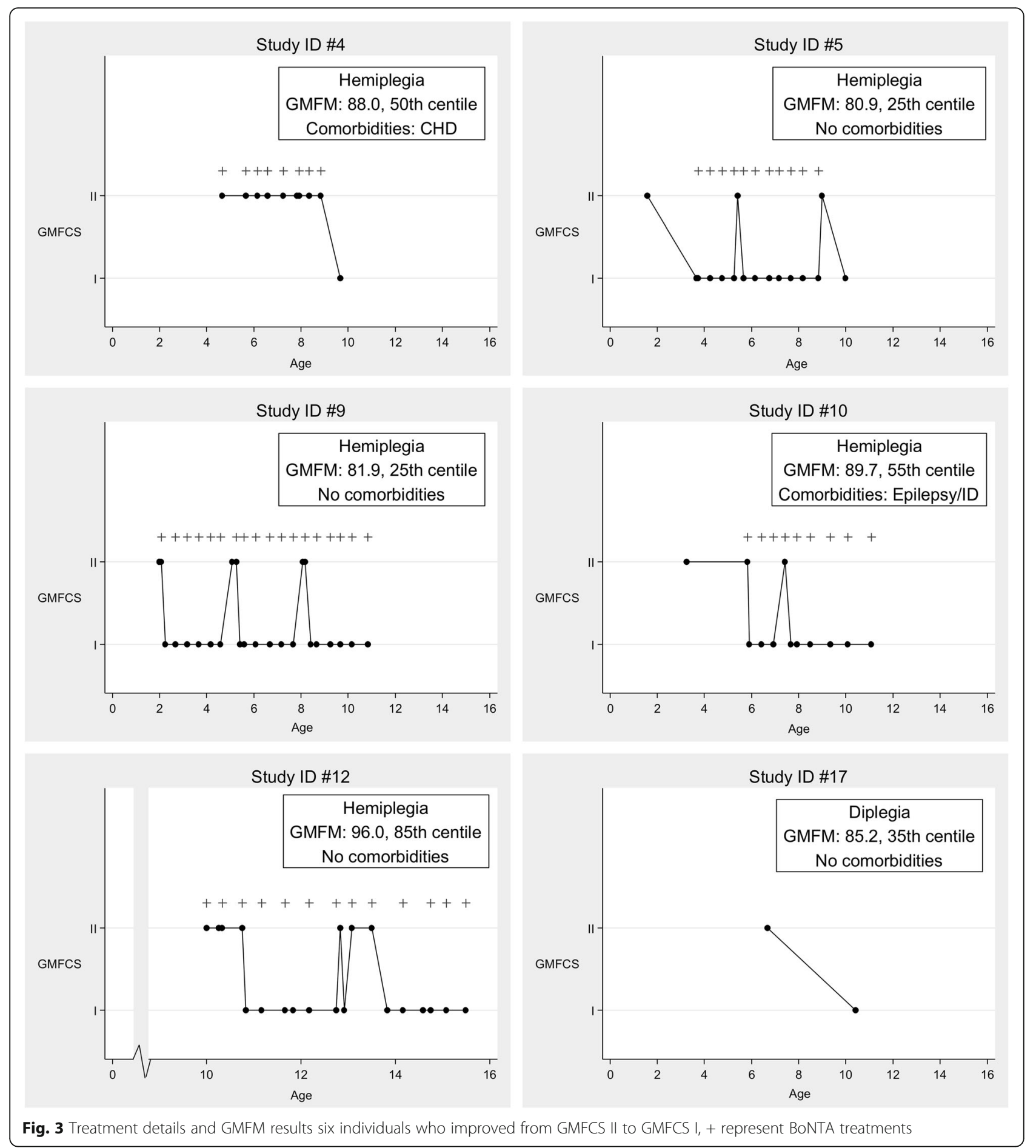

level is considered stable, and their GMFM-66 scores are in the high centile range, being at the 85th and 50th centile respectively for GMFCS level.

In the original GMFCS motor curves, children who had received BoNTA or intrathecal baclofen or who had undergone selective dorsal root rhizotomy were excluded as it was not then known how these relatively new interventions would influence gross motor function [43]. This study details the BoNTA interventions provided and confirms that the majority of our highly treated population remains at a stable GMFCS level and with the GMFM-66 average consistent with the original published average levels. Notably, in a significant percentage of our assessed population, the GMFCS 
Table 3 Participation and Environment Measure for Children and Youth (PEM-CY) and the relationship with topography, GMFCS and pain

\begin{tabular}{|c|c|c|c|c|c|c|c|}
\hline & \multirow[t]{3}{*}{ n (\%) } & \multicolumn{6}{|c|}{ Participation and Environment Measure for Children and Youth (PEM-CY) } \\
\hline & & \multicolumn{2}{|l|}{ Home Average } & \multicolumn{2}{|c|}{ School Average } & \multicolumn{2}{|c|}{ Community Average } \\
\hline & & median (IQR) & $\overline{p \text { value }}$ & median (IQR) & $\overline{p \text { value }}$ & median (IQR) & $p$ value \\
\hline Total PEMCY Complete & $25(89 \%)$ & $6.1(5.4,6.5)$ & NA & $3.6(3.4,4.6)$ & NA & $2.2(1.6,3.0)$ & NA \\
\hline \multicolumn{8}{|l|}{ Topography } \\
\hline Diplegia & $14(56.0 \%)$ & $6.1(5.2,6.5)$ & 0.826 & $3.5(3.0,5.0)$ & 0.659 & $2.1(1.6,3.9)$ & 0.510 \\
\hline Hemiplegia & $10(40.0 \%)$ & $6.2(5.4,6.5)$ & & $3.8(3.4,4.4)$ & & $2.5(2.1,3.0)$ & \\
\hline \multicolumn{8}{|l|}{ GMFCS } \\
\hline । & $5(20.0 \%)$ & $6.2(5.4,6.5)$ & 0.864 & $3.4(3.4,4.4)$ & 0.784 & $2.8(1.4,3.0)$ & 0.634 \\
\hline$\|$ & 20 (80.0\%) & $6.1(5.3,6.5)$ & & $3.7(3.2,4.6)$ & & $2.2(1.8,3.5)$ & \\
\hline \multicolumn{8}{|l|}{ Pain Present } \\
\hline$O(N A)$ & $2(8.0 \%)$ & $6.4(6.4,6.4)$ & 0.397 & $3.7(3.4,4.0)$ & 0.953 & $6.0(5.2,6.5)$ & 0.398 \\
\hline 1 (Yes) & $8(32.0 \%)$ & $6.2(6.0,6.6)$ & & $3.6(3.1,5.1)$ & & $3.6(3.4,4.6)$ & \\
\hline 2 (No) & 15 (60.0\%) & $6.0(5.2,6.5)$ & & $3.6(3.4,4.6)$ & & $2.2(1.6,2.8)$ & \\
\hline \multicolumn{8}{|l|}{$\mathrm{BMl}$} \\
\hline normal weight & 19 (76.0\%) & $6.2(5.4,6.5)$ & 0.659 & $3.6(3.4,4.6)$ & 0.903 & $2.2(1.6,3.0)$ & 0.781 \\
\hline overweight & $4(16.0 \%)$ & $6.0(5.2,6.2)$ & & $3.7(3.2,5.3)$ & & $2.3(1.4,3.8)$ & \\
\hline obese & $2(8.0 \%)$ & $5.9(5.0,6.7)$ & & $3.7(3.2,4.2)$ & & $3.2(2.1,4.4)$ & \\
\hline
\end{tabular}

improved over time and deteriorated in none. The decision to use BoNTA is multifactorial and guided by the CPMS model of goal-based decision making within the International Classification of Functioning, Disability and Health (ICF) model with input from a multidisciplinary team, parent(s) and, where appropriate, the child. In our clinical service the outcome of BoNTA treatment is evaluated by review of the child post BoNTA treatment that includes history for side effects, documentation of a technical response e.g. by change in Modified Ashworth, Modified Tardieu assessments, or reduction in spasm scores or Barry Albright dystonia score, and documentation of outcome of goals. A written report is submitted by the community therapists of the post intervention provided and information on the outcome of goals is also commented on in this report. Our doses of BoNTA are low to moderate [2] and our distribution of muscle use is similar to that of other Australian teams. All patients who receive BoNTA in our service must have a community therapy provider and when our patients receive medical or surgical intervention through our program, we also provide funding for extra postintervention therapy sessions from the community team. For example, if a patient receives lower limb BoNTA to one or to two limbs, they receive eight or 16 extra therapy sessions respectively.

It is well understood that comorbidities in children with $\mathrm{CP}$ affect the outcome, our rates of comorbidities

Table 4 Participation and Environment Measure for Children and Youth (PEM-CY) and Gross Motor Function Measure 66 (GMFM-66) association. GMFCS II only $(n=20)$

\begin{tabular}{llll}
\hline & \multicolumn{1}{l}{ GMFM Total Score } & & \\
\cline { 2 - 3 } & Coefficient $(95 \% \mathrm{Cl})$ & $p$ value & correlation coefficient (95\% Cl) \\
\hline PEMCY (outcome) & $0.04(-0.02,0.09)$ & $p=0.146$ & $0.34(-0.12$ to 0.68$)$ \\
Home average & $-0.05(-0.11,0.02)$ & $p=0.143$ & $-0.34(-0.68$ to 0.12$)$ \\
School average & $-0.02(-0.09,0.05)$ & $p=0.574$ & $-0.13(-0.54$ to 0.33$)$ \\
Community average & $0.01(-0.01,0.03)$ & $p=0.219$ & $0.29(-0.18$ to 0.65$)$ \\
GMFM centile (predictor) & $-0.02(-0.04,-0.01)$ & $p=0.014$ & $-0.54(-0.79$ to -0.13$)$ \\
Home average & $-0.01(-0.04,0.01)$ & $p=0.167$ & $-0.32(-0.67$ to 0.14$)$ \\
School average & & & \\
Community average & &
\end{tabular}


are similar to that documented by Novak [44] and the Australian Cerebral Palsy Register [45], and as expected the rate of comorbidities in those children who improved GMFCS level (33\%) was lower than in those whose GMFCS level remained stable (54\%). Increasing $\mathrm{BMI}$ is a significant issue for children of all abilities but a significant further risk factor for children with a motor impairment. Our rates of overweight and obese children are similar to those seen in typically developing children and children with CP [46-48].

The dimension of participation is an important inclusion in the ICF [49] and as it is clear that participation contributes to quality of life [50] an important target of our treatment is to provide increased participation. In our cohort of children there was no statistically significant relationship between PEM-CY scores and topography, final GMFCS level or pain scores. The statistically significant negative association between school participation and GMFM is not easily understood and likely multifactorial. Anecdotally what is seen is that children with CP who have good motor function but not the level of motor function equivalent to that of typically developing children are or tend to be isolated in motor-based school activities as they cannot keep up with their peers.

It is known from recent large population cohort studies on GMFCS level stability that a percentage of patients in each GMFCS level change levels over time and there have been recent calls in the literature to study the comorbidities and treatments received by those subgroups of children with a permanent change in GMFCS level $[40,51]$. To our knowledge, this study is the first to provide detailed information on medical interventions and comorbidities of individuals with $\mathrm{CP}$ in relationship to GMFCS level stability.

\section{Limitations}

The major limitation of this study is the absence of a GMFM-66 assessment at time point 1. As the aim of this study was to look at GMFCS stability in a treated population we limited our cohort to children whose first GMFCS level recorded was level II as these children have potential to change GMFCS level in both directions, but motor function is not reported to decline in adolescence [42]. Only a randomly selected 28 of the 40 eligible children were assessed. Table 1 suggests that they may have been a relatively good outcome group, but the differences are not marked. This study focuses on BoNTA treatment as this is the most frequent major intervention at this GMFCS level, in particular this study does not provide details concerning the type of surgery. We do not report any adverse side effects of BoNTA in this paper since there have been several recent papers on this subject $[9,10,52]$ including our own [53]. The impact of repeat dosing with BoNTA on muscle structure and function has not been studied in this paper but is recognised to be an important consideration in the long-term use of BoNTA. We have recently published on the impact on muscle volume and muscle structure following repeat dosing of BoNTA and presently we aim to minimise the dose of BoNTA used, rotate muscle selection where possible and ensure post intervention strength training, where appropriate [54-56]. It is now recognised that children with $\mathrm{CP}$ from socioeconomically disadvantaged settings are more likely to have reduced motor functional outcomes [57]; this study has not looked at any socio-economic determinants of health but this would be important in future research.

\section{Conclusion}

This cohort study has confirmed that children with CP and a GMFCS level of II treated at a young age with repeated low to moderate doses of BoNTA within an integrated comprehensive service, maintain their functional motor gains at a later age.

\section{Abbreviations \\ BMI: Body mass index; BoNTA: Botulinum toxin type A; \\ CFCS: Communication Function Classification System; CHD: Congenital heart disease; CP: Cerebral Palsy; CPMS: Cerebral Palsy Mobility Service; GMAE- \\ 2: Gross Motor Ability Estimator; GMFCS: Gross Motor Function Classification System; GMFM-66: Gross Motor Function Measure; ICF: International \\ Classification of Functioning, Disability and Health; ID: Intellectual disability; ILD: Interstitial lung disease; IQR: Interquartile range; LD: Learning difficulties; MACS: Manual Ability Classification System; NA: Not applicable; PCH: Perth Children's Hospital; PEM-CY: The Participation and Environment Measure for Children and Youth; PNI: Peripheral nerve injury; SD: Standard Deviation; WA: Western Australia}

\section{Acknowledgements}

We would like to thank the parents and children who participated in this study. We also acknowledge and thank all the staff of the Perth Children's Hospital Cerebral Palsy Management Service and Professor Peter Rosenbaum.

\section{Authors' contributions}

$J V$ developed the specific study hypothesis, conducted data analysis and wrote the primary draft of the manuscript. SAD, NB, EB, LP, RW, DF and CE provided guidance in developing the statistical approach and data analysis and provided critical inputs on successive manuscript drafts. All authors approved the final manuscript for publication. Consent for Publication by $B M C$ paediatrics is agreed to and completed.

\section{Funding}

The GMFM assessment time was funded by an unrestricted post graduate education grant from Allergan. This funding body, Allergan had no role in the design of the study, collection, analysis or interpretation of data or writing of the manuscript. The content is solely the responsibility of the authors and does not necessarily represent the official views of the funders. All of the above authors report they have no other declarations of interest financial or non-financial.

\section{Availability of data and materials}

The datasets generated and/or analysed during the current study are not publicly available due to the guidelines of our Ethics Committee process. Data and material will be available upon reasonable request as deidentified data and after review of request by our institution's ethics committee, applications should be directed to the corresponding author at, jane. valentine@health.wa.gov.au. 


\section{Ethics approval and consent to participate}

The research involving human data reported in this paper was assessed and approved by Perth Children's Hospital Human Research Ethics Committees Number reference number 2016099 and The University of Western Australia Human Research Ethics Committee reference number RA/4/1/9374. Informed written consent was obtained from parents of all the children and adolescents with Cerebral Palsy who participated in this study and written assent from the adolescents where appropriate.

\section{Consent for publication}

Not applicable.

\section{Competing interests}

The authors declare that they have no competing interests.

\section{Author details}

'School of Medicine, University of Western Australia, 35 Stirling Highway, Crawley, Western Australia 6009, Australia. ${ }^{2}$ Department of Paediatric Rehabilitation, Perth Children's Hospital, Nedlands, Western Australia, Australia. ${ }^{3}$ Department of Child Research, Child Adolescent Health Service, Nedlands, Western Australia, Australia. ${ }^{4}$ Telethon Kids Institute, Perth, Western Australia, Australia. ${ }^{5}$ School of Occupational Therapy, Social Work and Speech Pathology, Curtin University, Bentley, Western Australia, Australia.

\section{Received: 28 July 2019 Accepted: 26 December 2019}

\section{Published online: 06 January 2020}

\section{References}

1. Rosenbaum P, Paneth N, Leviton A, Goldstein M, Bax M. The definition and classification of cerebral palsy contents foreword historical perspective definition and classification document. Dev Med Child Neurol. 2007:49(109):8-14.

2. Heinen F, Desloovere K, Schroeder AS, Berweck S, Borggraefe I, van Campenhout A, et al. The updated European consensus 2009 on the use of Botulinum toxin for children with cerebral palsy. Eur J Paediatr Neurol. 2010; 14(1):45-66

3. Register ACP. ACPR Group. Report of the Australian Cerebral Palsy Register, Birth Years 1993-2003. 2009.

4. Valentine J, Davidson SA, Bear N, Blair E, Ward R, Thornton A, et al. Botulinum toxin and surgical intervention in children and adolescents with cerebral palsy: who, when and why do we treat? Disabil Rehabil. Aug. 2019; 15:1-8.

5. Vargus-Adams J, Martin LK. Domains of importance for parents, medical professionals and youth with cerebral palsy considering treatment outcomes. Child Care Health Dev. 2011;37:276-81.

6. Delgado MR, Hirtz D, Aisen M, Ashwal S, Fehlings DL, McLaughlin J, et al. Practice parameter: pharmacologic treatment of spasticity in children and adolescents with cerebral palsy (an evidence-based review): report of the Quality Standards Subcommittee of the American Academy of Neurology and the Practice Committee of the Child Neurology Society. Neurology. 2010;74(4):336-43.

7. Novak I, Mclntyre S, Morgan C, Campbell L, Dark L, Morton N, et al. A systematic review of interventions for children with cerebral palsy: state of the evidence. Dev Med Child Neurol. 2013;55(10):885-910.

8. Koman L, Smith B, Goodman A, Mulvaney T. Management of cerebral palsy with botulinum A toxin: preliminary investigation. J Paediatr Orthop. 1993; 13(4):489-95.

9. O'flaherty SJ, Janakan V, Morrow AM, Scheinberg AM, Waugh MA. Adverse events and health status following botulinum toxin type A injections in children with cerebral palsy. Dev Med Child Neurol. 2011;53(2):125-30.

10. Swinney CM, Bau K, Burton KLO, O'Flaherty SJ, Bear NL, Paget SP. Severity of cerebral palsy and likelihood of adverse events after botulinum toxin A injections. Dev Med Child Neurol. 2018;60(5):498-504.

11. Copeland L, Edwards P, Thorley M, Donaghey S, Gascoigne-Pees L, Kentish $M$, et al. Botulinum toxin A for nonambulatory children with cerebral palsy: a double blind randomized controlled trial. J Pediatr. 2014;165(1):140-6 e4.

12. Koman LA, Mooney JF 3rd, Smith BP, Walker F, Leon JM. Botulinum toxin type A neuromuscular blockade in the treatment of lower extremity spasticity in cerebral palsy: a randomized, double-blind, placebo-controlled trial. BOTOX study group. J Pediatr Orthop. 2000;20(1):108-15.
13. Love SC, Valentine JP, Blair EM, Price CJ, Cole JH, Chauvel PJ. The effect of botulinum toxin type $\mathrm{A}$ on the functional ability of the child with spastic hemiplegia a randomized controlled trial. Eur J Neurol. 2001;8(Suppl 5):50-8.

14. Boyd RN, Pliatsios V, Starr R, Wolfe R, Graham HK. Biomechanical transformation of the gastroc-soleus muscle with botulinum toxin A in children with cerebral palsy. Dev Med Child Neurol. 2000;42(1):32-41.

15. Steenbeek D, Meester-Delver A, Becher JG, Lankhorst GJ. The effect of botulinum toxin type $A$ treatment of the lower extremity on the level of functional abilities in children with cerebral palsy: evaluation with goal attainment scaling. Clin Rehabil. 2005;19(3):274-82.

16. Linder M, Schindler G, Michaelis U, Stein S, Kirschner J, Mall V, et al. Medium-term functional benefits in children with cerebral palsy treated with botulinum toxin type A: 1-year follow-up using gross motor function measure. Eur J Neurol. 2001;8:120-6.

17. Tedroff K, Granath F, Forssberg H, Haglund-Akerlind Y. Long-term effects of botulinum toxin A in children with cerebral palsy. Dev Med Child Neurol. 2009;51(2):120-7.

18. Hoare BJ, Wallen MA, Imms C, Villanueva E, Rawicki HB, Carey L. Botulinum toxin $A$ as an adjunct to treatment in the management of the upper limb in children with spastic cerebral palsy (UPDATE). Cochrane Database Syst Rev. 2010;20(1):CD003469.

19. Lorin K, Forsberg A. Treatment with botulinum toxin in children with cerebral palsy: a qualitative study of parents' experiences. Child Care Health Dev. 2016;42(4):494-503.

20. Delgardo MR, Tilton A, Russman B, Benavides O, Gormley ME, et al. Abobotulinumtoxin A for equinus foot deformity in cerebral palsy: a randomized controlled trial. Pediatrics. 2017;137(2):e20152830.

21. Molenaers G, Van Campenhout A, Fagard K, De Cat J, Desloovere K. The use of botulinum toxin $A$ in children with cerebral palsy, with a focus on the lower limb. J Child Orthop. 2010;4(3):183-95.

22. Kahraman A, Seyhan K, Deger U, Kutluturk S, Mutlu A. Should botulinum toxin A injections be repeated in children with cerebral palsy? A systematic review. Dev Med Child Neurol. 2016;58(8):910-7.

23. Hastings-Ison T, Blackburn C, Rawicki B, Fahey M, Simpson P, Baker R, et al. Injection frequency of botulinum toxin A for spastic equinus: a randomized clinical trial. Dev Med Child Neurol. 2016;58(7):750-7.

24. Matthews DJ. Frequency of botulinum toxin injections for spastic equinus: how much is enough? Dev Med Child Neurol. 2016;58(7):657-8.

25. Gough M. Does botulinum toxin prevent or promote deformity in children with cerebral palsy? Dev Med Child Neurol. 2009;51(2):89-90.

26. Gough M, Fairhurst C, Shortland AP. Botulinum toxin and cerebral palsy: time for reflection? Dev Med Child Neurol. 2005;47(10):709-12.

27. McIntyre S, Novak I, Cusick A. Consensus research priorities for cerebral palsy: a Delphi survey of consumers, researchers, and clinicians. Dev Med Child Neurol. 2010;52(3):270-5.

28. Gross PH, Bailes AF, Horn SD, Hurvitz EA, Kean J, Shusterman M. Setting a patient-centered research agenda for cerebral palsy: a participatory action research initiative. Dev Med Child Neurol. 2018;60(12):1278-84.

29. Palisano R, Rosenbaum P, Walter S, Russell D, Wood E, Galuppi B. Development and reliability of a system to classify gross motor function in children with cerebral palsy. Dev Med Child Neurol. 1997;39(4):214-23.

30. Russell DJ, Rosenbaum PL, Avery L, Lane M. Gross motor function measure (GMFM-66 and GMFM-88) user's manual: clinics in developmental medicine. London: Mac Keith Press; 2002.

31. Hanna SE, Bartlett DJ, Rivard LM, Russell DJ. Reference curves for the gross motor function measure: percentiles for clinical description and tracking over time among children with cerebral palsy. Phys Ther. 2008;88(5):596-607.

32. Daut RL, Cleeland CS, Flanery RC. Development of the Wisconsin brief pain questionnaire to assess pain in cancer and other diseases. Pain. 1983;17(2): 197-210.

33. Coster W, Bedell G, Law M, Khetani MA, Teplicky R, Liljenquist K, et al. Psychometric evaluation of the participation and environment measure for children and youth. Dev Med Child Neurol. 2011;53(11):1030-7.

34. Palisano RJ, Rosenbaum P, Bartlett D, Livingston MH. Content validity of the expanded and revised gross motor function classification system. Dev Med Child Neurol. 2008;50(10):744-50.

35. Mitchell LE, Ziviani J, Boyd RN. Characteristics associated with physical activity among independently ambulant children and adolescents with unilateral cerebral palsy. Dev Med Child Neurol. 2015;57(2):167-74.

36. Russo RN, Miller MD, Haan E, Cameron ID, Crotty M. Pain characteristics and their association with quality of life and self-concept in children with 
hemiplegic cerebral palsy identified from a population register. Clin J Pain. 2008:24(4):335-42

37. Breau LM, Camfield CS, McGrath PJ, Finley GA. The incidence of pain in children with severe cognitive impairments. Arch Pediatr Adolesc Med. 2003;157(12):1219-26.

38. Berrin SJ, Malcarne VL, Varni JW, Burwinkle TM, Sherman SA, Artavia K, et al. Pain, fatigue, and school functioning in children with cerebral palsy: a pathanalytic model. J Pediatr Psychol. 2007;32(3):330-7.

39. Parkinson KN, Dickinson HO, Arnaud C, Lyons A, Colver A. Pain in young people aged 13 to 17 years with cerebral palsy: cross-sectional, multicentre European study. Arch Dis Child. 2013;98(6):434

40. Alriksson-Schmidt A, Nordmark E, Czuba T, Westbom L. Stability of the gross motor function classification system in children and adolescents with cerebral palsy: a retrospective cohort registry study. Dev Med Child Neurol. 2017:59(6):641-6.

41. Palisano RJ, Avery L, Gorter JW, Galuppi B, McCoy SW. Stability of the gross motor function classification system, manual ability classification system, and communication function classification system. Dev Med Child Neurol. 2018;60(10):1026-32.

42. Hanna SERP, et al. Stability and decline in gross motor function among children and youth with cerebral palsy. Dev Med Child Neurol. 2009;51(4): 295-302.

43. Rosenbaum PL, Walter S, Hanna S, et al. Prognosis for gross motor function in cerebral palsy: creation of motor development curves. JAMA. 2002; 288(11):1357-63.

44. Novak I. Evidence-based diagnosis, health care, and rehabilitation for children with cerebral palsy. J Child Neurol. 2014;29(8):1141-56.

45. Australian Cerebral Palsy Register G. Report-of-the-Australian-Cerebral-PalsyRegister-Birth-Years-1995-2012. 2018.

46. Xu J, Hardy LL, Guo CZ, Garnett SP. The trends and prevalence of obesity and morbid obesity among Australian school-aged children, 1985-2014. J Paediatr Child Health. 2018;54(8):907-12.

47. Pascoe J, Thomason P, Graham HK, Reddihough D, Sabin MA. Body mass index in ambulatory children with cerebral palsy: a cohort study. J Paediatr Child Health. 2016;52(4):417-21.

48. Bansal A, Diwan S, Diwan J, Vyas N. Prevalance of obesity in children with cerebral palsy. J Clin Diagn Res. 2014;8(8):BC08-11.

49. Ustun TB, Chatterii S, Bickenbach J, Kostanjsek N, Schneider M. The international classification of functioning, disability and health: a new tool for understanding disability and health. Disabil Rehabil. 2003;25(11-12):565-71.

50. Bedell GM, Khetani MA, Cousins MA, Coster WJ, Law MC. Parent perspectives to inform development of measures of children's participation and environment. Arch Phys Med Rehabil. 2011;92(5):765-73.

51. Gisel EG. Stability of three classification systems for cerebral palsy: benefits from multicenter collaboration. Dev Med Child Neurol. 2018;60(10):970-1.

52. Kolaski K. Botulinum toxin: did the black box warning change how we treat children with cerebral palsy? Dev Med Child Neurol. 2018;60(5):440-1.

53. Langdon K, Blair E, Davidson SA, Valentine J. Adverse events following botulinum toxin type A treatment in children with cerebral palsy. Dev Med Child Neurol. 2010;52(10):972-3 author reply 974.

54. Williams SA, Reid S, Elliott C, Shipman P, Valentine J. Muscle volume alterations in spastic muscles immediately following botulinum toxin type-A treatment in children with cerebral palsy. Dev Med Child Neurol. 2013;55(9):813-20.

55. Alexander C, Elliott C, Valentine J, Stannage K, Bear N, Donnelly CJ, et al. Muscle volume alterations after first botulinum neurotoxin $\mathrm{A}$ treatment in children with cerebral palsy: a 6-month prospective cohort study. Dev Med Child Neurol. 2018;60(11):1165-71.

56. Valentine J, Stannage K, Fabian V, Ellis K, Reid S, Pitcher C, et al. Muscle histopathology in children with spastic cerebral palsy receiving Botulinum toxin type a. Muscle Nerve. 2016;53:407-14.

57. Woolfenden S, Galea C, Smithers-Sheedy H, Blair E, McIntyre S, Reid S, et al. Impact of social disadvantage on cerebral palsy severity. Dev Med Child Neurol. 2019;61(5):586-92.

\section{Publisher's Note}

Springer Nature remains neutral with regard to jurisdictional claims in published maps and institutional affiliations.

Ready to submit your research? Choose BMC and benefit from:

- fast, convenient online submission

- thorough peer review by experienced researchers in your field

- rapid publication on acceptance

- support for research data, including large and complex data types

- gold Open Access which fosters wider collaboration and increased citations

- maximum visibility for your research: over $100 \mathrm{M}$ website views per year

At BMC, research is always in progress.

Learn more biomedcentral.com/submissions 